\title{
The influence of $\mathrm{Li}_{2} \mathrm{CO}_{3}$ on the kinetics of the concrete hardening at the temperature of $80^{\circ} \mathrm{C}$
}

\author{
Aleksey Adamtsevich ${ }^{1,{ }^{*}}$, Ivan Blinov ${ }^{1}$, Liubov Shilova ${ }^{1}$, Andrey Pustovgar ${ }^{1,2}$ and Ekaterina \\ Shokodko ${ }^{1}$ \\ ${ }^{1}$ Moscow State University of Civil Engineering, 129337, 26, Yaroslavskoye Sh., Moscow, Russia \\ ${ }^{2}$ Science Center for Nonlinear Wave Mechanics and Technology, Institute of Machine Science, \\ Russian Academy of Sciences, (NTs NVMT IMASh), Moscow, Russia
}

\begin{abstract}
The present work was done during the research carried out by the authors, the aim of which was to develop methods for reducing energy costs in the manufacture of precast concrete and reinforced concrete structures for civil engineering. The paper presents the results of the analysis of the addition of lithium carbonate $\left(\mathrm{Li}_{2} \mathrm{CO}_{3}\right)$ effect on the rate of hydration of Portland cement and the concrete obtained on its basis under high temperature conditions $\left(80^{\circ} \mathrm{C}\right)$. The heat release curves were obtained during the hydration of samples based on a cement binder using the isothermal calorimetry method. The addition of $\mathrm{Li}_{2} \mathrm{CO}_{3}$ was taken in dosages from $0.5 \%$ to $2.0 \%$ by weight of cement. The graphical dependences of the heat release of the exothermic hydration reaction from the used dosage of lithium carbonate in the first 10 hours of hardening are established and presented in the paper. The obtained heat release data were compared with the graphs of the hardening of the samples tested by the standard method.
\end{abstract}

\section{Introduction}

The tasks of increasing labor productivity, optimizing costs, improving environmental friendliness and reducing harmful emissions in all areas of industrial production become more relevant at the present stage of the human society. All these problems are especially relevant in the production of building materials for Civil engineering - the most resourceintensive branch of human economy. Moreover, in all developed countries the issue of increasing the energy efficiency of the technological process and reducing the energy costs of manufacturing of a product unit becomes more urgent at the factories where prefabricated reinforced concrete structures and concrete products are produced.

The optimization of the concrete mixtures compositions and the introduction of various modifying additives into their composition reduce the hardening time of concrete, which allows saving energy resources at the heat treatment stage while maintaining the turnover of the molds. This approach also makes it possible to increase the turnover of molds while the set values of energy consumption for heat treatment of manufactured products are curing.

\footnotetext{
* Corresponding author: AdamtsevichAO@mgsu.ru
} 
Ultimately, any of the measures ensures a decrease of the energy intensity of a product unit and reduces $\mathrm{CO} 2$ emissions to the atmosphere [1,2].

For a long time the additives such as sodium chloride, soda ash, sodium thiosulfate, etc., were the most common additives regulating the speed of setting and hardening of cement systems in the building industry. However, due to the fact that chloride ions can cause corrosion of steel reinforcement, and sodium salts lead to deterioration concrete products appearance [3-5], today the search of effective accelerating additives that haven't similar effects is very actual and popular question.

One of such additives can be lithium carbonate (Li2CO3). At the same time, according to the authors' studies [6] it has been established that unlike most other known accelerator additives, lithium carbonate significantly increases the intensity of the exothermic hydration reaction of individual Portland cement samples not only at normal and lower temperatures, but also at a higher temperature corresponding to the conditions of heat treatment in the manufacture of reinforced concrete products in the factory.

In this regard, the purpose of this research work was to make an additional study of the synergistic potential of using a lithium carbonate additive as an accelerating additive for cement systems hardening in the heat-moisture treatment mode used at many ferro-concrete products factories.

\section{Materials and methods}

All studies in the present article were carried out on samples of CEM I $42.5 \mathrm{~N}$ cement of Russian origin from one batch. The particle size distribution of the cement sample, determined by laser diffraction on an Analysette 22 particle size analyzer, is shown in Table 1 and in Fig. 1. The results of the chemical and phase composition determination of cement obtained using the X-ray fluorescence spectrometer ARLOptim'X are presented in Table 2 and in Fig. 2.

Table 1. The granulometric composition of the studied sample of Portland cement.

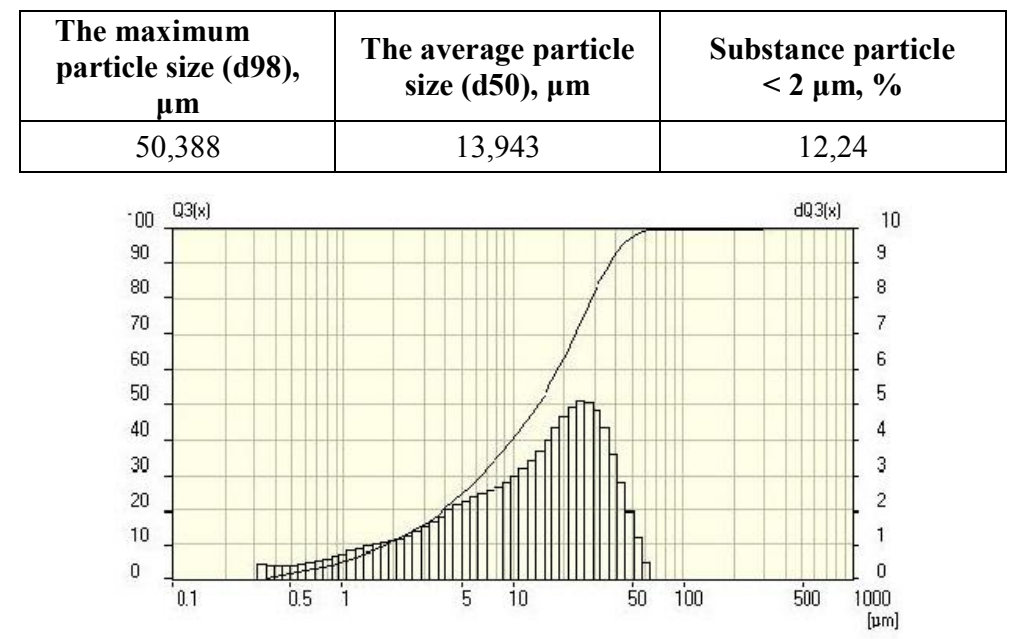

Fig. 1. The integral and differential curve of particle size distribution for the studied sample of Portland cement. 
Table 2. Chemical and mineralogical composition of Portland cement.

\begin{tabular}{|c|c|c|c|}
\hline \multicolumn{2}{|c|}{ Chemical composition } & \multicolumn{2}{|c|}{ Mineralogical composition } \\
\hline Oxide & Content $* \%$ & Phase & Content, \% \\
\hline $\mathrm{CaO}$ & 61,91 & C3S & 64,0 \\
\hline $\mathrm{SiO} 2$ & 20,42 & $\beta-\mathrm{C} 2 \mathrm{~S}$ & 11,7 \\
\hline $\mathrm{Al} 2 \mathrm{O} 3$ & 4,84 & $\mathrm{C} 3 \mathrm{~A}$ & 4,6 \\
\hline $\mathrm{MgO}$ & 4,76 & $\mathrm{C} 4 \mathrm{AF}$ & 12,2 \\
\hline $\mathrm{SO} 3$ & 3,80 & $\begin{array}{c}\text { Double-gypsum } \\
\text { plaster }\end{array}$ & 1,3 \\
\hline $\mathrm{Fe} 2 \mathrm{O} 3$ & 3,07 & $\begin{array}{l}\text { Semi-water } \\
\text { gypsum }\end{array}$ & 2,2 \\
\hline $\mathrm{K} 2 \mathrm{O}$ & 0,539 & Periclase & 2,5 \\
\hline $\mathrm{TiO} 2$ & 0,239 & $\mathrm{~K} 2 \mathrm{Ca}(\mathrm{CO} 3) 2$ & 1,5 \\
\hline $\mathrm{SrO}$ & 0,129 & & \\
\hline $\mathrm{Na} 2 \mathrm{O}$ & 0,104 & & \\
\hline $\mathrm{MnO}$ & 0,0855 & & \\
\hline $\mathrm{P}$ & 0,0305 & & \\
\hline $\mathrm{ZnO}$ & 0,0231 & & \\
\hline $\mathrm{CuO}$ & 0,0169 & & \\
\hline $\mathrm{ZrO} 2$ & 0,0142 & & \\
\hline $\mathrm{Cr} 2 \mathrm{O} 3$ & 0,0097 & & \\
\hline $\mathrm{Co} 3 \mathrm{O} 4$ & 0,0049 & & \\
\hline $\mathrm{NiO}$ & 0,0042 & & \\
\hline
\end{tabular}

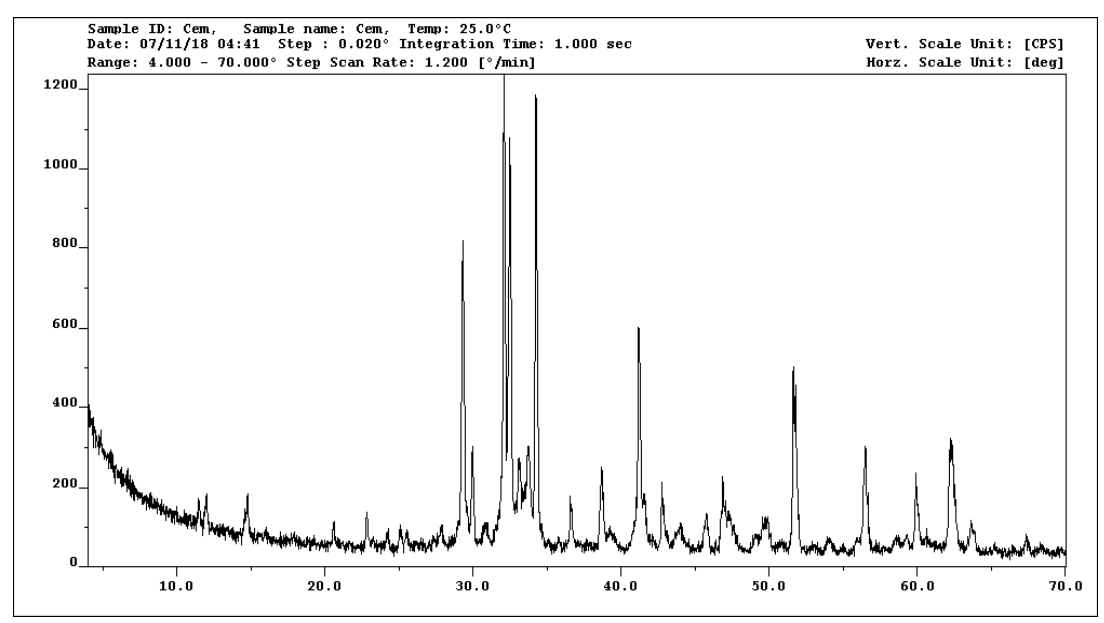

Fig. 2. The registered diffractogram of Portland cement.

Lithium carbonate (LI2CO3), supplied by Eurochem-1, was used as an accelerating additive in the present study. A list of the formulations and dosages of the additive in the samples is presented in Table 3 . 
Table 3. Studied samples.

\begin{tabular}{|c|c|c|}
\hline No & Title & $\begin{array}{c}\text { The content of Li2Co3, \% } \\
\text { by weight of cement }\end{array}$ \\
\hline 1 & Control & 0 \\
\hline 2 & $0,5 \%$ & 0,5 \\
\hline 3 & $1,0 \%$ & 1,0 \\
\hline 4 & $2,0 \%$ & 2,0 \\
\hline
\end{tabular}

The effect of the additive on the rate of concrete hardening was studied in the interval of 0-10 hours of hardening by analyzing the heat of cement hydration, and also by the standard method for determining the compressive strength of control samples in accordance with EN 196-1.

The additive was previously dispersed separately from the solid phase in the mixing water with a ULTRA TURAX T-50basic dissolver for $1 \mathrm{~min}$ at a speed of $1000 \mathrm{rpm}$ to improve the homogeneity of the mixture.

The measurement of the heat generation of cement paste samples hydration was carried out using an 8-channel TAM AIR isotreme calorimeter with an air thermostat programmed to maintain a temperature of $80^{\circ} \mathrm{C}$ inside each channel. Samples of cement paste with a water-cement ratio of 0.5 weight about 4 grams were immersed in glass ampoules and hermetized throughout the measurement. The analysis of the results reproducibility for two parallel measurements in different channels for a given temperature regime are shown in Fig. 3.

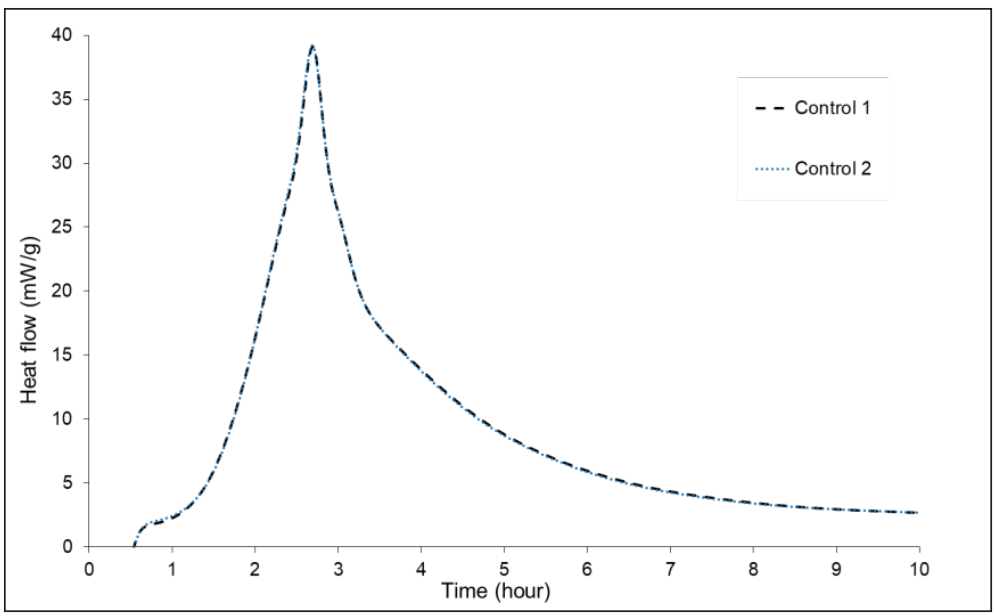

Fig. 3. The reproducibility of exothermic cement hydration curves for two parallel measurements at $80^{\circ} \mathrm{C}$.

The strength characteristics of the samples were determined through the Controls Advantest-9 multi-channel servo-hydraulic press. The prepared mixture was molded into preheated metal molds, after that the samples were placed in an accelerated hardening chamber, maintaining an isothermal temperature of $80^{\circ} \mathrm{C}$.

All samples were removed from the mold after the first 3 hours of aging in the chamber, and then returned to it without molds for further maintenance. The samples were tested every hour between 3 and 10 hours of incubation. 


\section{Results}

The graphs of the heat flux and integral graphs of the total thermal energy of the samples which were investigated though the isothermal calorimetry method are shown in Fig.4 and Fig.5. Table 4 shows the average strength values of the tested control samples at different times. The graphical form of the hardening of the test samples are presented in Fig.6

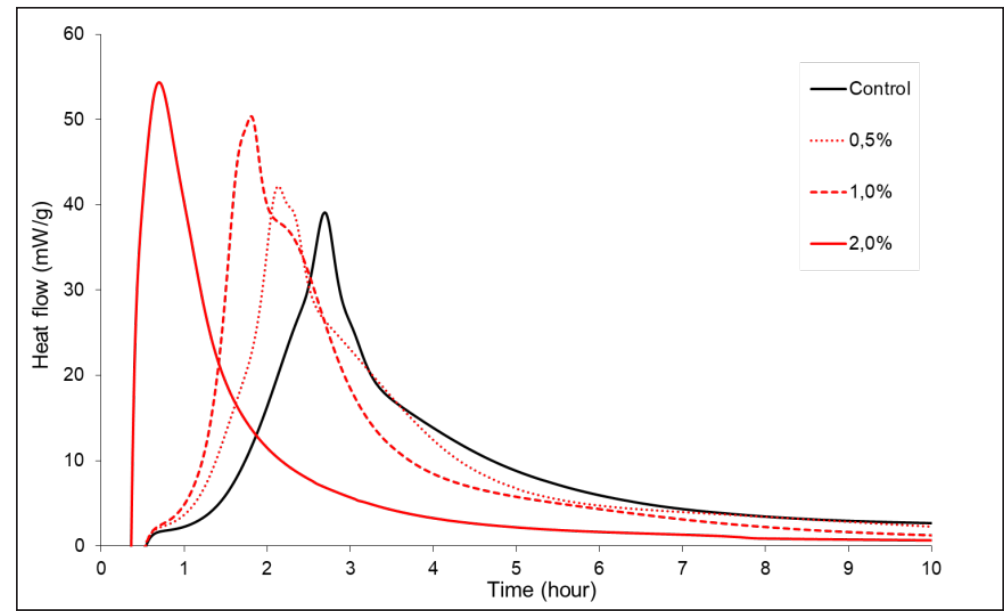

Fig. 4. The heat release of hydration.

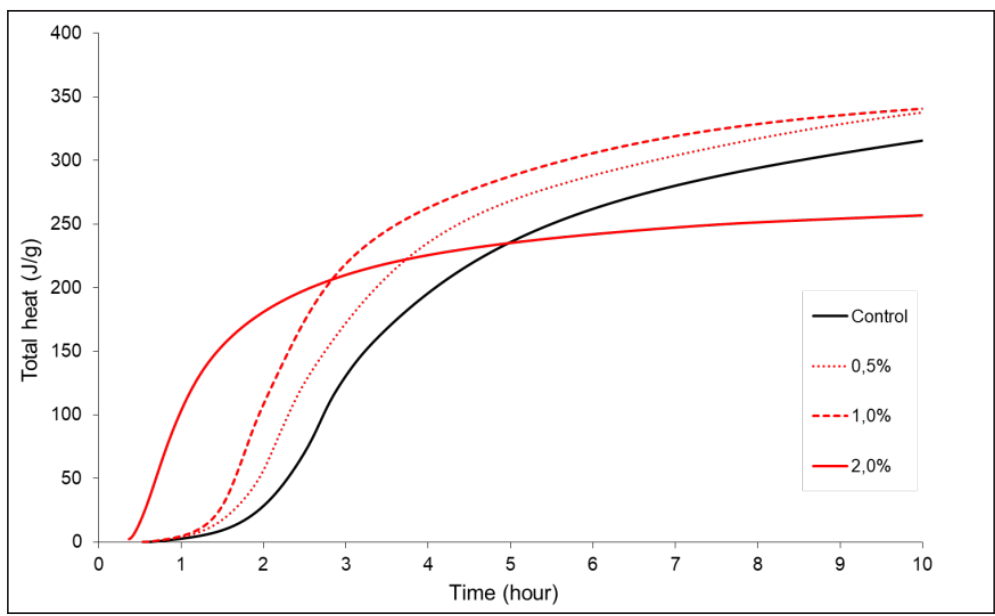

Fig. 5. The integral graphs of the thermal energy of hydration 
Table 4. The average values of compressive strength

\begin{tabular}{|c|c|c|c|c|}
\hline \multirow{2}{*}{$\begin{array}{c}\text { Time, } \\
\text { hour }\end{array}$} & \multicolumn{4}{|c|}{ Compressive strength for different specimens, MPa } \\
\cline { 2 - 5 } & Control & $\mathbf{0 , 5 \%}$ & $\mathbf{1 , 0 \%}$ & $\mathbf{2 , 0} \%$ \\
\hline 3 & 9,16 & 9,68 & 13,93 & 13,70 \\
\hline 4 & 15,23 & 16,53 & 16,68 & 14,95 \\
\hline 5 & 19,40 & 20,81 & 20,25 & 15,03 \\
\hline 6 & 23,07 & 22,41 & 25,46 & 16,25 \\
\hline 7 & 25,64 & 24,77 & 26,99 & 16,55 \\
\hline 8 & 27,57 & 26,84 & 29,53 & 17,46 \\
\hline 9 & 31,37 & 28,59 & 31,77 & 17,17 \\
\hline 10 & 31,89 & 29,35 & 32,22 & 16,40 \\
\hline
\end{tabular}

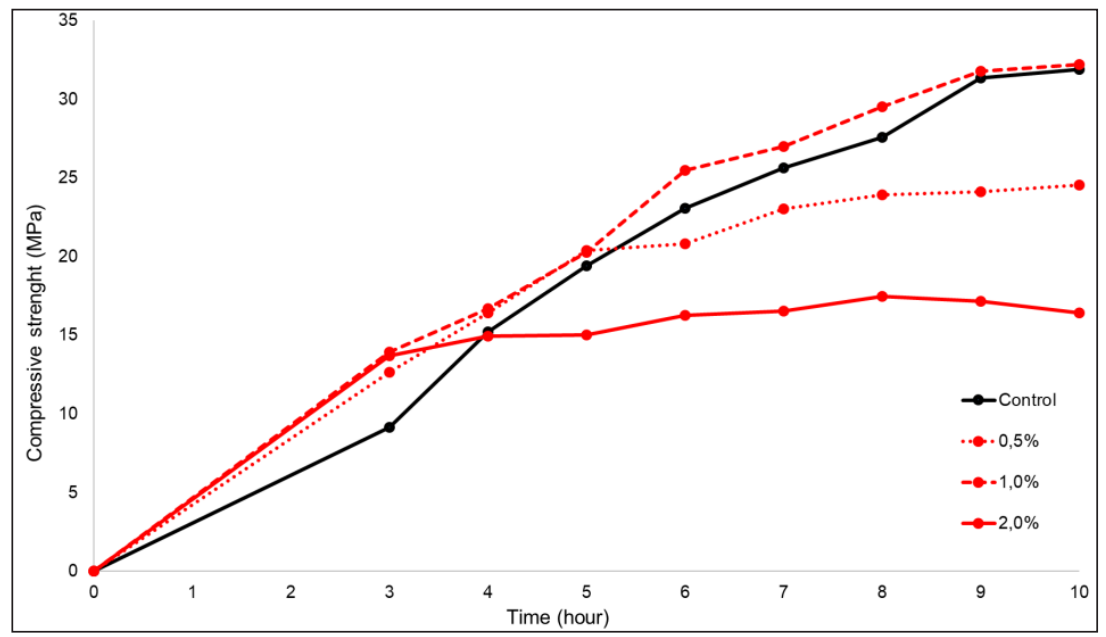

Fig. 6. The graphs of the hardening of the test samples

\section{Discussion}

The analysis of calorimetry data shows that for samples which was kept at elevated temperature $\left(80^{\circ} \mathrm{C}\right)$, the addition of lithium carbonate in the mixture leads to a reduction of the induction period of the hydration process, as well as to an increase the intensity and displacement of the maximum peaks of heat release to earlier stages (Fig. 4). At the same time, this effect increases proportionally to the growth of the dosage of the additive, that leads to the total absence of the induction period when an additive dosage is about $2 \%$. At the same time, the addition of the accelerator makes it possible to achieve an appreciable growth in the early strength only in the first 3-4 hours (Fig. 6) after the start of maintaining the samples, that also agrees well with the graphs of the total thermal energy of the samples hydration (Fig.5).

At later periods of hardening, the samples with the additive in most cases gained strength more slowly than the control sample, or did not allow making a conclusion that the addition of the additive was sufficient enough to shorten the periods of concrete heat treatment in the manufacture of reinforced concrete products in the factory. Thus, the most effective dosage of the additive in the range of $4-10$ hours was a dosage of $1.0 \%$ by weight of cement, but the average strength values of the samples with the indicated dosage of the additive were only slightly higher than those for the control sample. At the same time the 
sample containing additive in a dosage of $2 \%$ by weight of cement, shows the values of strength almost twice lower than the control sample in 10 hours. This result was even smaller than the values predicted [7,8] from the calorimetry data (Fig. 5). This fact can be explained, among other things, by the appearance of defects in the form of longitudinal cracks with a width of $0.1-0.3 \mathrm{~mm}$ in the upper part of many samples containing lithium carbonate in high dosages (Fig. 7).
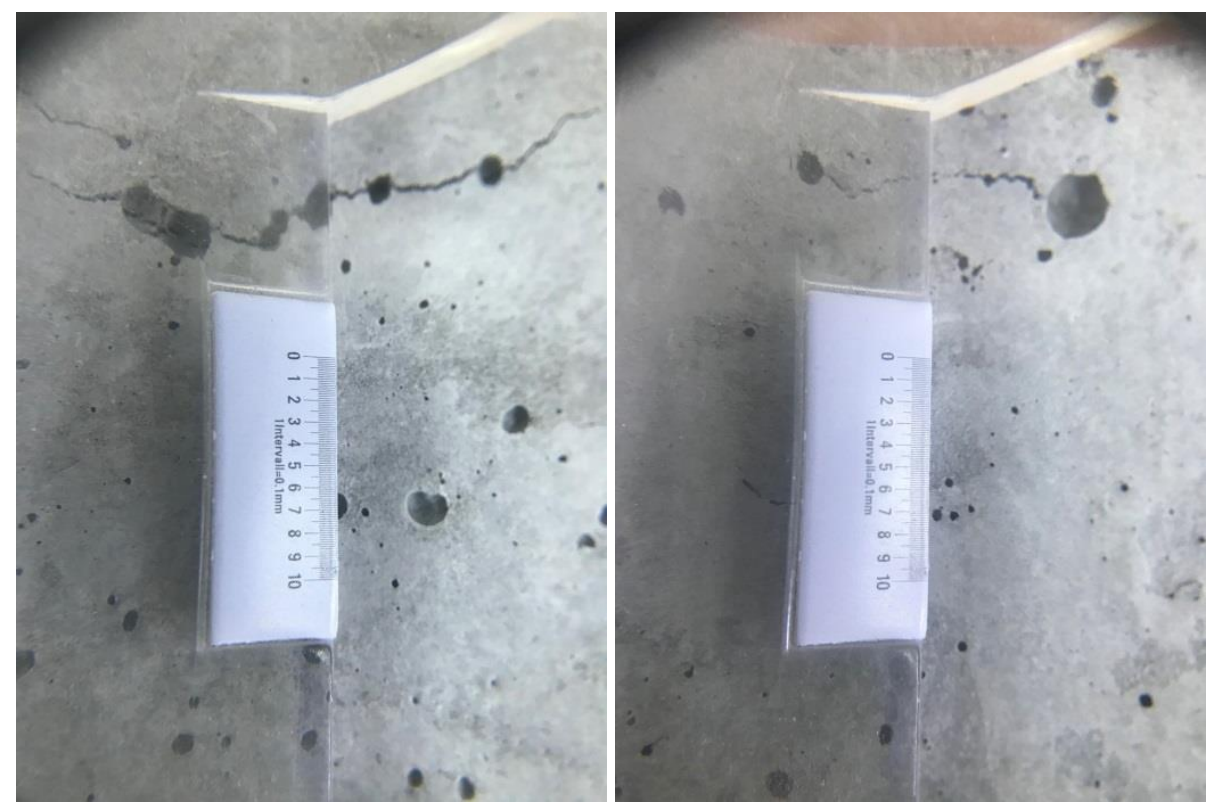

Fig. 7. Cracks on the control samples

\section{Conclusion}

Eventually, it has been established that the addition of the additive Li2 $\mathrm{CO} 3$ in pure form at a dosage of $0.5 \%$ to $2.0 \%$ into concrete mixture based on Portland cement CEM I $42,5 \mathrm{~N}$ does not allow to achieve an expected for this study stage result fully. It is mean that the addition of the additive, even in the optimal tested dose (1.0\% by weight of cement), does not solve the problem of reducing the energy intensity of industrial production of reinforced concrete products with existing technological process.

It has also been established that high doses of lithium carbonate in the cement mixture composition lead to increasing defects formation in concrete products. This fact may be related with a high rate of loss of mobility mixture due to the absence of an induction period (Fig. 4), and high intensity of the heat release of the mixture from self-heating in the first minutes after the beginning of the samples aging.

At the next stages of this research work the authors plan to solve this problem and make further investigations of the additive efficiency by the using it as a part of a concrete mixture with plasticizing and surface-active additives.

This work was supported by the Ministry of Education and Science of Russia (\#14.Z56.3456-MK), all tests were carried out on the equipment of The Head Regional Shared Research Facilities of the Moscow State University of Civil Engineering. 


\section{References}

1. V.G. Mikylskiy, G.I. Gorchyakov, V.V. Kozlov, Building materials (ASV, Moscow, 2002)

2. U.M. Bazhenov, Concrete technology (ASV, Moscow, 2007)

3. J. Cheung, and others, Cem. Concr. Res., Impact of admixtures on the hydration kinetics of Portland cement, 41-12, 1289-1309 (2011)

4. I. Pane, W. Hansen, Cem. Concr. Res., Investigation of blended cement hydration by isothermal calorimetry and thermal analysis, 35-6, 1155-1164 (2005)

5. T. Aberle, A. Pustovgar, ALITinform: Cement. Concrete. Dry Mixtures, Prevention of efflorescence formation on masonry structures of buildings and constructions, 6, 64-70 (2008)

6. A.O. Adamtsevich, L. Shilova, IOP Conf. Ser.: Earth Environ, The regulation of hardening kinetics of building composites based on cement binders, Sci. 90012152 (2017)

7. A.O. Adamtsevich, S.A. Pashkevich, A.P. Pustovgar, Civ. Eng. M., Applicatiom of calorimetry for prognosticating strength increase of fast-curing cement systems, 38, 36-42 (2013)

8. A. Rodin, V. Erofeev, A. Pustovgar, and others, Vestnik MGSU, Kinetics of Strength Gain of Biocidal Cements, 12, 88-97 (2014) 